$\overline{\overline{\text { BRUSSELS }}} \overline{\overline{\text { STUDIES }}}$

\section{Brussels Studies}

La revue scientifique électronique pour les recherches sur Bruxelles / Het elektronisch wetenschappelijk tijdschrift voor onderzoek over Brussel / The e-journal for academic research on Brussels

Notes de synthèse | 2009

\title{
Brussel, een kennisregio?
}

Synthesenota, SGB nr. 12

Bruxelles, région de la connaissance?

Brussel, een kennisregio?

\section{Benjamin Van Camp et Olivier Witmeur}

Traducteur : Ben Winant

\section{OpenEdition}

\section{Journals}

Édition électronique

URL : http://journals.openedition.org/brussels/982

DOI : 10.4000/brussels.982

ISSN : 2037-0293

Éditeur

Université Saint-Louis Bruxelles

Référence électronique

Benjamin Van Camp en Olivier Witmeur, «Brussel, een kennisregio? », Brussels Studies [Online]

Synthesenota's, Online op 09 février 2009, geraadpleegd op 01 mai 2019. URL : http:// journals.openedition.org/brussels/982 ; DOI : 10.4000/brussels.982 
www.brusselsstudies.be

\author{
ÉTATS GÉNÉRAUX DE \\ STATEN-GENERAAL VAN \\ CITIZENS'FORUM OF \\ RUXELLES \\ RUSSEL \\ RUSSELS \\ www.statengeneraalvanbrussel.be
}

Synthesenota nr. 12

\section{Brussel, een kennisregio?}

\author{
B. Van Camp, O. Witmeur \\ Vertaling : Ben Winant
}

- Benjamin Van Camp is ererector van de Vrije Universiteit Brussel (00-08), medisch diensthoofd in het UZBrussel en voorzitter van de onderzoeksgroep Hematologie faculteit Geneeskunde VUB. Hij is voorzitter van het Strategisch Comité Universitair Beleid van het UZBrussel en lid van verschillende wetenschappelijke en administratieve bestuursraden.

Contact : ben.vancamp@uzbrussel.be - ++32 (0)2/477.62.11

- Olivier Witmeur is docent Ondernemerschap aan de Solvay Brussels School of Economics and Management (ULB). Hij is ook voorzitter van de Raad voor het Wetenschapsbeleid van het Brussels Hoofdstedelijk Gewest en bestuurder van verschillende innoverende KMO's.

Contact : olivier.witmeur@ulb.ac.be - ++32(0)2/650.41.61

Discussieavond:

16 februari, $19 u 45$

IHECS

Rue de l'Etuve 58-60 1000 Brussel 


\section{Vaststellingen}

\section{Het belang van kennis voor Europa en Brussel}

Brussel telt meer dan 70.000 studenten in het hoger onderwijs. De op academisch onderzoek en/of praktische ervaring gebaseerde kennis wordt doorgegeven op de universiteitscampussen en in de hogescholen die in de 19 gemeenten zijn gevestigd. In het hoger onderwijs zijn meer dan 14.000 docenten, assistenten, onderzoekers en administratief-technische personeelsleden aan de slag. Die uitzonderlijke concentratie van onderwijs- en onderzoeksactiviteiten zou - in principe - Brussel in de kopgroep van de actoren van de kennismaatschappij moeten plaatsen.

De ontwikkeling van een kennismaatschappij sluit aan bij de evolutie van de productiefactoren van de economieën. De belangrijkste productiefactoren waren oorspronkelijk arbeid en kapitaal, maar kennis wordt heden ten dage beschouwd als een derde essentiële pijler van de Westerse economieën. De economische, sociale en ecologische ontwikkeling vereisen eveneens innovatie en ontwikkeling van nieuwe kennis in academische (bijv. universiteiten) en industriële opleidings- en onderzoekscentra (bijv. ondernemingen van verschillende grootte) of in verschillende 'denktanken'. Daarom moedigt de Europese Unie de lidstaten ertoe aan de uitgaven voor onderzoek en ontwikkeling (O\&O) aanzienlijk op te voeren met als einddoel 3\% van het bruto binnenlands product.

De O\&O-activiteiten zijn in Brussel wellicht meer dan elders van cruciaal belang, want ze moeten een economisch weefsel mede tot stand brengen dat aangepast is aan de kenmerken van een stadsgewest. Jammer genoeg staan ze zelden centraal in de debatten over de toekomst van het Gewest, omdat ze op korte termijn onvoldoende zichtbare resultaten opleveren. 


\section{Kenniseconomie berust op ontwikkeling en valorisatie van onderzoek}

Valorisatie van de onderzoeksresultaten en ontwikkeling van een kennismaatschappij impliceren de controle over een waardeketen die van begin tot einde een breed spectrum van activiteiten omvat, met inbegrip van basis- of voortgezette opleiding, fundamenteel onderzoek, toegepast onderzoek, ontwikkelingsactiviteiten, oprichting van nieuwe organisaties (of nieuwe structuren binnen bestaande entiteiten) die belast worden met de valorisatie van het onderzoek, en de verdere uitbouw van die organisaties. Bovendien vereist de goede werking van die keten een reeks ondersteunende activiteiten, zoals beheer van de intellectuele eigendom, wetenschappelijke evaluatie, technisch-commerciële evaluatie, managementbegeleiding, financiering en uitbouw van onthaalinfrastructuur... Als men Brussel als kennisregio wil profileren, dan moet men al die activiteiten onder controle hebben.

\section{Het Brussels Hoofdstedelijk Gewest beschikt over beperkte bevoegdheden inzake wetenschapsbeleid.}

In België zijn de Gemeenschappen bevoegd voor de persoonsgebonden aangelegenheden en de Gewesten voor de grondgebiedgebonden aangelegenheden. De Gemeenschappen zijn bijgevolg bevoegd voor onderwijs en het daaraan verbonden onderzoek: dat omvat fundamenteel en toegepast onderzoek aan de universiteiten en de geassocieerde hogescholen, wetenschappelijke vulgarisatie en de wetenschappelijke instellingen die onder de Gemeenschappen ressorteren. De Gewesten zijn bevoegd voor economische steun en technologische innovatie en voor de onderzoeksactiviteiten in dat verband. Die bevoegdheid omvat de basissteun aan de industrie, het uitwerken van nieuwe producten en processen en de overdracht van technologie. De federale overheid is ten slotte bevoegd voor de federale wetenschappelijke instellingen en voor het nucleair en ruimteonderzoek. Het Brussels Hoofdstedelijk Gewest heeft bijgevolg een beperkt werkterrein en kan de waardeketen alleen in samenwerking met andere gezagsniveaus volledig beheren. De gewestelijke operatoren worden ook geconfronteerd met de beperkte afmetingen van het Brussels grondgebied en de beperkte bevoegdheden van het Brussels Hoofdstedelijk Gewest en bevinden zich regelmatig in een moeilijke situatie tegenover de andere Gewesten en Gemeenschappen.

\section{Weinig beschikbare gegevens voor de studie over de situatie in Brussel}

Het Brussels Hoofdstedelijk Gewest beschikt over weinig statistieken en studies om zijn wetenschappelijk beleid en steun aan innovatie te bepalen, te sturen en te evalueren. Het merendeel van de beschikbare gegevens komt uit vergelijkingen tussen de Gewesten of de Gemeenschappen en zelfs uit Europese studies, die een onvolledig beeld van de situatie in het Brussels Gewest verstrekken. Bovendien zijn de beschikbare gegevens grotendeels toegespitst op een bepaalde schakel in de waardeketen, terwijl een geïntegreerde benadering van essentiel belang is. De volgende gegevens geven weliswaar een eerste idee van de situatie in Brussel, maar zijn te beperkt om grondigere analyses te kunnen uitvoeren. 
5. Onderzoek in Brussel is een zeer belangrijke economische activiteit op zich en sterk uitgebouwd in de academische wereld, maar minder goed uitgebouwd in de industrie

In Brussel zijn meer dan 13.000 personen betrokken bij wetenschappelijk onderzoek, onder wie meer dan 9.000 onderzoekers ${ }^{1}$. Bij wijze van vergelijking, in Vlaanderen zijn dat er meer dan 47.000 (onder wie meer dan 27.000 onderzoekers) en in Wallonië meer dan 18.000 (onder wie meer dan 11.000 onderzoekers). Na een grondigere analyse van die cijfers blijkt dat het wetenschappelijk onderzoek in Brussel, in vergelijking met de overige twee Gewesten, meer banen biedt in de academische sector (ongeveer 2/3 van de werkgelegenheid) dan in de industriesector (ongeveer $1 / 3$ van de werkgelegenheid), terwijl die verhouding omgekeerd is in de overige Gewesten.

Met twee volledige universiteiten (ULB, VUB), twee onvolledige universiteiten (FUSL, $\mathrm{K}(\mathrm{H}) \cup B$ ), de faculteit Geneeskunde van de $U C L$, een groot aantal hogescholen en instellingen voor hoger onderwijs (bijv. de Vinci, de Brouckère, Spaak, Erasmus, EHSAL, Haute Ecole de Bruxelles, Ferrer, de groep ICHEC - ISC Saint-Louis ISFSC, La Cambre...) en drie universitaire ziekenhuizen (UCL, ULB, VUB), telt het Brussels Gewest een groot aantal onderzoekers en beschikt het over een benijdenswaardig potentieel. Jammer genoeg zijn de Brusselse bedrijven wegens de structuur van het industrieel weefsel van het Gewest minder innoverend dan de bedrijven in de buurgewesten ${ }^{2}$. Het wetenschappelijk potentieel dat bij het begin van de keten voorhanden is, wordt dus niet altijd verderop in de keten benut wanneer het erom gaat de onderzoeksresultaten te valoriseren. In het Gewest ontbreken er beslissingscentra van gevestigde bedrijven en ondernemers die bereid zijn om bedrijven met een groot groeipotentieel uit te bouwen. Bovendien worden de middelen (voorzieningen, financiële middelen...) verspreid over een groot aantal actoren die hun eigen logica volgen (studenten, onderwijscentra, onderzoekscentra, grote bedrijven, kleine bedrijven, mono- of bicommunautaire instellingen...). Aangezien het logisch is dat onderzoeksinstellingen hun kennis valoriseren met economische partners die soms ook buiten het Gewest gevestigd zijn, zou het aangewezen zijn om een beter Brussels institutioneel kader tot stand te brengen dat de relaties tussen de verschillende partners regelt.

\section{Kenniseconomie is meer dan enkel O\&O}

Naast de traditionele bio- en toegepaste wetenschappen, heeft het onderzoek in de sociale en humane wetenschappen een hoge vlucht genomen. De kennis van die wetenschappen heeft niet alleen een grote impact op de sociaaleconomische ontwikkeling van de dienstenactiviteiten, maar ook op de evolutie van onze opvattingen en op de organisatie zelf van onze samenleving. Een mooi voorbeeld daarvan is het onderzoek over de specifieke kenmerken van Brussel (cf. de publicaties van 'Brussels Studies'), dat de diversiteit, multiculturaliteit, meertaligheid en het vraagstuk van de sociale integratie grondig bestudeert en tot nieuwe initiatieven op verschillende niveaus leidt.

\footnotetext{
${ }^{1}$ Bron: internetsite van het federale wetenschapsbeleid (www.belspo.be)

${ }^{2}$ CIS-enquête 2006.
} 
De verdere uitbouw van de kennismaatschappij en innovatie hangen niet alleen af van het aanmoedigen van onderzoek, maar zijn ook gebaat bij een klimaat dat creativiteit bevordert. Zo'n klimaat vinden we zowel in de academische wereld als in het artistiek-culturele milieu.

Als grootste studentenstad van het land, centrum van belangrijke onderzoeksactiviteiten en vestigingsplaats van een groot aantal culturele-artistieke tempels bevindt Brussel zich in een ideale positie om antwoorden te vinden voor de problemen die gepaard gaan met de dualiteit en culturele diversiteit die de stad kenmerken. In die context zal de keuze voor grote openbare werken zoals Urbizone, Brussels Wireless Network of stadsvernieuwing van essentieel belang zijn om de bevolking te doen warmlopen voor een nieuwe dynamiek.

7. De Brusselse Hoofdstedelijke Regering heeft al een aantal keuzen gemaakt, maar die blijven vrij algemeen

De Brusselse Hoofdstedelijke Regering heeft in haar regeerprogramma 2004-2009 erkend dat er tot dan toe onvoldoende inspanningen waren geleverd op het vlak van onderzoek en ontwikkeling. Tijdens de laatste regeerperiode (nog aan de gang) heeft het Gewest aanzienlijk meer middelen uitgetrokken en die hoofdzakelijk geïnvesteerd in projecten waarbij de universiteiten samenwerken om de resultaten in het Gewest te valoriseren ${ }^{3}$. De maatregelen van de regering zijn hoofdzakelijk gericht op drie zeer ruim gedefinieerde sectoren:

- Informatie- en communicatietechnologieën;

- Gezondheidssector;

- Leefmilieu.

Het Gewestplan stelt eveneens zes strategische assen voor:

- As 1: Promotie van de drie innoverende sectoren. Het is de bedoeling om clustervorming in die sectoren te bevorderen;

- As 2: Versterking van de verwezenlijking van innovatie. Daartoe zijn impulsprogramma's opgezet;

- As 3: Stimuleren van de valorisatie van innovatie via commercialisering van de resultaten van het onderzoek en bijstand aan kleine ondernemingen om ze vertrouwd te maken met de innovaties en die te leren gebruiken;

- As 4: De nadruk leggen op de internationalisering van innovatie;

- As 5: Aantrekken en verankeren van innoverende activiteiten;

- As 6: Scheppen van een gunstige omgeving voor innovatie.

${ }^{3}$ Cf. de jaarverslagen van het IWOB en de Raad voor het Wetenschapsbeleid van het Brussels Hoofdstedelijk Gewest. 
8. De instrumenten van het gewestelijk beleid ter ondersteuning van de innovatie zijn grosso modo vergelijkbaar met die van de overige Gewesten

De studie van Dulbea (Capron \& Hadjit, 2007) over het WTI-beleid (Wetenschap, Technologie en Innovatie) besluit dat dit beleid vrij recent is, maar dat het Brussels Gewest tijdens de afgelopen jaren een reeks instrumenten heeft ingevoerd die tegemoetkomen aan de behoeften van de onderzoekers. Het Brussels Gewest is zich bewust van het belang van het onderzoeks- en innovatiebeleid voor zijn ontwikkeling en heeft zijn begrotingskredieten voor O\&O de laatste jaren verhoogd.

Het Brussels Gewest heeft een aantal initiatieven opgezet die vergelijkbaar zijn met wat in de overige Gewesten bestaat:

- verschillende types van onderzoekssubsidies voor alle soorten actoren;

- oprichting van een specifiek bestuur, namelijk het IWOIB (Instituut ter bevordering van het Wetenschappelijk Onderzoek en de Innovatie van Brussel);

- steun aan teams die instaan voor de overdracht van technologie van de universiteiten en hogescholen;

- oprichting van verschillende incubatoren;

- aanmoediging van durfkapitaal;

- ...

Niettemin trekt het Brussels Gewest nog steeds minder middelen voor O\&O uit dan zijn buurgewesten. Bovendien worden de Brusselse initiatieven vaak ondergebracht in verschillende organisaties, zodat de schaalvoordelen gering zijn en de coördinatie soms moeilijk verloopt.

9. De doelstellingen van het onderzoek reiken veel verder dan het gewestelijk kader, maar Brussel heeft een unieke positie als nationale en Europese hoofdstad

Het spreekt voor zich dat de doelstellingen van het onderzoek en de 'uitmuntendheid' waarnaar in dat verband gestreefd wordt, zeer snel botsen met een aanpak die zich tot het Gewest beperkt. Dat valt des te meer op, daar het Brussels Hoofdstedelijk Gewest klein is en over weinig middelen beschikt. Ondanks zijn centrale ligging heeft het Gewest geen gestructureerde samenwerking met externe partners opgezet, noch voor de begeleiding van onderzoeksprojecten noch voor de valorisatie van de onderzoeksresultaten. Het is dan ook noodzakelijk om beter samen te werken met andere regio's en het onderzoek beter te coördineren met de Europese initiatieven (bijvoorbeeld opeenvolgende kaderprogramma's, European Institute for Technology, eengemaakte Europese onderzoeksruimte, ...). 


\section{Gebrek aan coördinatie binnen het Gewest}

Het Brussels Gewest heeft onvoldoende bevoegdheden om de logistieke en infrastructurele samenwerking tussen, enerzijds, de 19 gemeenten en, anderzijds, de onderzoeks- en onderwijsinstellingen te begeleiden en te coördineren.

Die instellingen kampen constant met een groot gebrek aan infrastructuur (gebouwen, woningen, voorzieningen...) en aanverwante algemene diensten om hun aantrekkingskracht te vergroten. Vandaag moet men bij elk initiatief rekening houden met regels die van gemeente tot gemeente verschillen en het gebeurt niet zelden dat de loutere aanwezigheid van een instelling op het gemeentelijk grondgebied als een 'bron van hinder' wordt ervaren. Samenwerkingsovereenkomsten tussen de instellingen en de lokale overheden zijn zo goed als onbestaand. Het bestaan van verschillende beslissingsniveaus in het Brussels Gewest zet een rem op de uitvoering van het beleid om de aantrekkingskracht van Brussel op studenten en onderzoekers te vergroten. In tegenstelling tot steden zoals Antwerpen, Gent, Luik, en Leuven, kunnen de kritieke behoeften aan infrastructurele hulp niet worden vervuld wegens het ontbreken van gezamenlijke maatregelen tussen het Gewest en de verschillende instellingen van het hoger onderwijs.

Alleen al op gewestelijk vlak stelt men tevens vast dat de bevoegdheden inzake ondersteuning en valorisatie van het onderzoek uitgeoefend worden via een groot aantal instrumenten (zie vaststelling 8)

\section{Weinig aandacht voor de sociale en humane wetenschappen}

Hoewel de sociale en humane wetenschappen goed vertegenwoordigd zijn in de academische wereld, worden er zelden specifieke projecten opgezet om hun ontwikkeling aan te moedigen. Ze vallen bijvoorbeeld niet onder de strategische assen van het Gewestelijk Plan voor Innovatie. 


\section{Vragen-problemen}

1. Welke soort projecten steunen?

- Wat zijn de meest geavanceerde sectoren in Brussel? Welke mogelijkheden bieden ze in elke schakel in de waardeketen? Heeft de gezondheidssector niet het grootste potentieel in Brussel?

- Moet het Brussels Gewest zijn troeven (bijvoorbeeld de gezondheidssector) uitspelen of trachten nieuwe capaciteiten te ontwikkelen die meer gericht zijn op sectoren van de toekomst (bijvoorbeeld leefmilieu)?

- Dient transdisciplinair onderzoek naar belangrijke onderzoeksonderwerpen niet te worden aangemoedigd?

- Welke synergieën kan het Gewest ontwikkelen met de initiatieven van de andere Gewesten, de federale Staat en de Europese Unie?

- Zijn de beleidskeuzes van het gewestelijk beleid niet te breed? Worden de lokale initiatieven grootschalig genoeg om te kunnen concurreren met andere regio's in Europa of in de wereld?

- Moet men in het beleid niet voluit de kaart trekken van 'multidisciplinary centres of excellence' die de instellingen virtueel verbinden (e.g. Vlaams Instituut voor Biotechnogie) en aldus interinstitutionele 'kennisplatformen' vormen?

\section{Dient er een 'Brussels University' te worden opgericht?}

- Zou het, gelet op de vorige vraag, niet oordeelkundig zijn om enkele wervende projecten (advanced Masters, interdisciplinary centres of excellence...) op te zetten via een instelling die het Gewest als internationaal platform gebruikt?

- Hoe kan men een dergelijke infrastructuur opzetten, rekening houdend met het institutionele kader waarbinnen de Brusselse universiteiten moeten functioneren?

- Gaat het enkel om onderzoek en innovatie? Is er geen behoefte aan een meeromvattende aanpak die ook rekening houdt met het onderwijs en de economische valorisatie?

- Vermits de internationale kaart getrokken wordt, kan men er dan van uitgaan dat het Engels de voertaal van de University of Brussels zal zijn en dat de marketing in het Engels zal gebeuren?

3. Zou men niet de onderzoeksactiviteiten zelf beter moeten ondersteunen?

- Zou men Brussel niet aantrekkelijker voor onderzoekers moeten maken door het aanbod aan ondersteunende diensten te verbeteren: taalpraktijk, administratieve formaliteiten, huisvesting, buurtdiensten, logistieke steun en uitbouw van infrastructuur...? 
4. Hoe kan de samenwerking tussen de verschillende actoren worden verbeterd?

- Hoe kan men de academische researchcentra en de bedrijven nader tot elkaar brengen?

- Hoe kunnen de gemeentelijke en gewestelijke overheden beter samenwerken bij het behandelen van de aanvragen om logistieke en infrastructurele steun vanwege de instellingen voor hoger onderwijs en onderzoek?

- Hoe kan het Gewest samenwerken met andere Gewesten en Gemeenschappen? Hoe kan het Gewest meer voordeel halen uit de Europese initiatieven?

- Heeft het Gewest niet te veel organisaties opgericht om onderzoek en innovatie te ondersteunen? Is het geen tijd om het dienstaanbod te rationaliseren (bijvoorbeeld: toenadering tussen de IWOIB, de dienst voor innovatie van het $\mathrm{BAO}$ en de nieuwe vereniging Research in Brussels, fusie(s) tussen het zestal incubatoren, ...)?

- Hoe kan het Gewest de onderzoekscentra die Brussel als bevoorrecht studieobject hebben, nauwer doen samenwerken?

- Welke types actoren moeten aangemoedigd worden, rekening houdend met hun capaciteit om zich in Brussel te verankeren? 


\section{Mogelijke beleidsoplossingen}

\section{Een boordtabel voor onderzoek en innovatie in Brussel opstellen}

Om de positie van Brussel objectief in te schatten, de definitie van de prioriteiten van het Gewest te verfijnen en de impact van de bestaande initiatieven te evalueren, zou het wenselijk zijn dat het Gewest over eigen statistieken beschikt, zoals Vlaanderen met het Vlaams Innovatie-Instrumentarium en het O\&O-steunpunt. Het IWOIB zou zo'n instrumentarium kunnen beheren, als het daartoe de nodige middelen zou krijgen.

2. Strengere selectie bij de steun aan enkele grote projecten van het Gewest.

Drie criteria zouden van doorslaggevend belang moeten zijn bij de selectie van de door het Gewest gesteunde initiatieven;

- uitmuntendheid;

- de gevolgen voor Brussel (namelijk de sociaaleconomische aspecten via optimale integratie in de waardeketen) ;

- de gevolgen voor de Brusselaars (namelijk hun levenskwaliteit in de stad).

Geneeskunde en sociale wetenschappen zijn bijvoorbeeld twee gebieden die aan die drie criteria beantwoorden, zelfs als het moeilijker is om de onderzoeksresultaten van de sociale wetenschappen 'industrieel' te valoriseren, omdat zulks minder voor de hand ligt ${ }^{4}$.

Terzelfder tijd moet men erop toezien dat de projecten/teams die steun van het Gewest krijgen, wel degelijk waarde creëren en niet in de weg staan van nieuwe projecten/teams, die regelmatig in het onderzoekslandschap van het Gewest geïntegreerd moeten worden.

3. Strategisch en multidisciplinair onderzoek aanmoedigen dat fundamentele wetenschappen, biowetenschappen en sociale wetenschappen combineert en zoveel mogelijk gewestelijke actoren inschakelt

Het lijkt opportuun om het gewestelijk beleid toe te spitsen op een kleiner aantal meer strategische ${ }^{5}$ projecten of 'grote werken' (bijv. het uitbouwen van infrastructuur voor onderzoek op gebied van ICT, energie en/of leefmilieu) die het enerzijds mogelijk maken om duurzame capaciteit uit te bouwen voor het ondersteunen van maatschappelijke en economische innovaties met alle actoren die daartoe kunnen bijdragen, en die anderzijds de bevolking doen warmlopen voor die grote projecten. Zoals de Raad voor het Wetenschapsbeleid in zijn jaarverslag 2007 schrijft, gaat het in veel gevallen om multidisciplinair onderzoek, want de reële problemen van de kennismaatschappij zijn zo complex dat er geen 'monodisciplinaire' oplossing kan worden gevonden. Een programmagestuurde aanpak zou bijgevolg te verkiezen zijn boven een projectgestuurde aanpak. Strategisch basisonderzoek in een open en innovatieve geest wordt altijd in consortium aangepakt. Het onderzoek wordt vaak

\footnotetext{
${ }^{4}$ Er bestaan sinds enkele jaren spinoffs van onderzoekscentra op het gebied van sociale en humane wetenschappen.

${ }^{5}$ Cf Cornelis (2005 ; 2007 ; 2008)
} 
toegespitst op resultaten die bruikbaar zijn voor een hele industriesector in plaats van voor één enkele onderneming. Het strategisch basisonderzoek is onlosmakelijk verbonden met een ontwikkelingsplan naar exploitatie en realisatie van economische meerwaarde. De onderzoeksresultaten leiden doorgaans tot projecten voor toegepast O\&O met een kleiner aantal partners en volgens de logica van de markteconomie. Dergelijke onderzoeksprojecten zouden kunnen worden opgezet op gebieden zoals bijvoorbeeld meertaligheid, fertiliteitsbehandelingen, palliatieve zorg of robotica. 4. Voorrang voor financiering van projecten waaraan verschillende gewestelijke
actoren van bij het begin van de onderzoeksketen meewerken

Tegelijk met de bovenvermelde strategische projecten moeten de gewestelijke initiatieven steeds de banden tussen de academische wereld en de industrie aanhalen, want daar zit de zwakke schakel in de waardeketen in Brussel. Het Gewest kan bijvoorbeeld op verschillende niveaus van de waardeketen steun verlenen: doctoraatsthesissen in bedrijven, samenwerking tussen bedrijven en universiteiten bij door het Gewest gesubsidieerde projecten, systematische aanwezigheid van industriële specialisten in de beheersorganen van de instrumenten van het gewestelijk beleid, $\cdots$

Het Gewest moet er tevens op toezien dat het ondernemerschap in de kleine ondernemingen, maar ook in de grote ondernemingen en de onderzoekscentra wordt bevorderd. Dat soort bekwaamheden is immers noodzakelijk als men wil overgaan naar de fase van de sociaaleconomische exploitatie.

5. De initiatieven in het Gewest rationaliseren, hergroeperen rond een kleiner aantal actoren en laten coördineren door een gewestelijke semi-overheidsinstelling belast met onderzoek en innovatie, a priori het IWOIB

Er dient minstens een diagnose van de doeltreffendheid van de huidige initiatieven tot ondersteuning van onderzoek en innovatie te worden gesteld. Daarnaast dienen de mogelijkheden op het vlak van integratie en vereenvoudiging zonder taboes te worden geanalyseerd (dit soort initiatief wordt beter toevertrouwd aan een onafhankelijke - idealiter buitenlandse - actor). Men dient ook na te gaan welke acties uitgebreid moeten worden. Tevens dienen de bevoegdheden inzake onderzoek en economie binnen de gewestregering op elkaar te worden afgestemd (dat is thans het geval, maar dat gebeurt niet systematisch wanneer de regeringen gevormd worden).

In dat vooruitzicht dient ook het onthaal van de hoofdactor van de innovatie, namelijk de onderzoeker en de student als potentiële toekomstige onderzoeker of valorisatie-actor te worden verbeterd. Brussel zou de kwaliteit van de diensten en de arbeidsvoorwaarden voor de hoofdactoren moeten verbeteren, zoals Leuven, Antwerpen, Gent en Luik dat hebben gedaan. Die steden voeren een krachtdadig beleid om de aanwezigheid van creatieve centra rond de universiteiten, hogescholen, cultuurtempels en onderzoeksinstellingen te faciliteren. In al die steden is een schepen bevoegd om relaties tussen de verschillende actoren te verbeteren en waar nodig met beschikbare middelen te ondersteunen. 


\section{De nieuwe strategische projecten groeperen in een Brussels University}

Het is niet de bedoeling om een nieuwe organisatie uit het niets op te richten, maar om geleidelijk de ondersteunende diensten die de Brusselse universiteiten en hogescholen beter niet apart aanbieden, samen te voegen. Nadat een aantal rationaliseringen zijn doorgevoerd in het gewestelijk onderzoekslandschap, zou die nieuwe structuur de ondersteunende diensten aanbieden en een reeks nieuwe initiatieven uitwerken (zoals de voornoemde strategische programma's en de uitbouw van een contactennetwerk of een coördinatie-infrastructuur tussen de onderzoeksactoren in Brussel). Het is natuurlijk ook de bedoeling om voordeel te halen uit Brussels rol als Europese hoofdstad. Die organisatie zou ook snel opleidingsprogramma's met internationale uitstraling opzetten die uit de samenwerking tussen verschillende gewestelijke actoren resulteren. De keuze van het Engels als voertaal wordt verantwoord door de internationale dimensie van het project.

\section{Betere coördinatie met de andere deelgebieden: een vrome wens?}

Het is geenszins onze bedoeling een institutioneel debat te voeren, maar het lijkt evident om aan win-winsamenwerkingen met de overige Gewesten en Gemeenschappen te denken. Eenvormige procedures, vereenvoudigde mechanismen om samenwerking met actoren van buiten het Gewest tot stand te brengen en meer flexibiliteit met betrekking tot de plaatsen waar de onderzoeksresultaten industrieel gevaloriseerd worden, zouden voor geen onoverkomelijke problemen mogen zorgen.

\section{De metropolitane en internationale dimensie versterken}

Het merendeel van de voorgestelde beleidsopties wordt ingegeven door de gewestelijke dimensie van Brussel. Men moet echter rekening houden met de metropolitane en internationale dimensie van de initiatieven voor kennisopbouw en van de desbetreffende valorisatie. Er moet meer aandacht worden besteed aan transregionale en transnationale samenwerking, onder meer door systematischer (met een proactieve aanpak) voordeel te halen uit de Europese initiatieven of uit de initiatieven die de institutionele grenzen van het Brussels Gewest overstijgen. 


\section{Referenties}

www.belspo.be, Statistiques de R\&D

www.brusselsstudies.be

CAPRON H. \& HADJIT A. (2007) Les dispositifs d'aide à l'innovation en Région de Bruxelles-Capitale : une mise en perspective aux niveaux belge et européen, Etude réalisée pour la Région de Bruxelles-Capitale, Dulbea, ULB.

CORNELIS J. (2005) «Fostering Research, Innovation and Networking», in How Open is the Future?, ed. by M. WYNANTS, J. CORNELIS, VUB Brussels University Press, Belgium, pp. 309-354

CORNELIS J. (2007) Strategic Research in support of Innovation, ppt. Bezoek van de Vorsten aan lerland (8 - 10 oktober 2007)

CORNELIS J. (2008) Models for knowledge and technology transfer and societal innovation, ppt. Visit of Hanoi technological University - IUS project (23 October1 November 2008)

CPSRBC (2007) Conseil de la Politique Scientifique de la Région de Bruxelles-Capitale - Rapport annuel 2007

Gouvernement de la Région de Bruxelles-Capitale (2006) Plan Régional pour l'Innovation.

IRSIB (2007) Institut d'encouragement de la Recherche Scientifique et de l'Innovation de Bruxelles - Rapport d'activités 2007.

Politique Scientifique Fédérale (2008) L'innovation en Belgique, résultat de l'enquête européenne CIS 2006. 